Diabetologia (1994) 37:278-285

\title{
Microvascular and acute complications in IDDM patients: the EURODIAB IDDM Complications Study
}

\author{
This manuscript was prepared by J.Stephenson and J.H. Fuller on behalf of the EURODIAB IDDM \\ Complications Study Group \\ The EURODIAB IDDM Complications Study Group \\ EURODIAB, Department of Epidemiology and Public Health, University College London, London, UK*
}

Summary The prevalence of microvascular and acute diabetic complications, and their relation to duration of diabetes and glycaemic control were examined in a cross-sectional study of 3250 IDDM patients in Europe (EURODIAB IDDM Complications Study). Mean (SD) duration of diabetes was 14.7 (9.3) years. $\mathrm{HbA}_{1 \mathrm{c}}$ and AER were measured centrally. Retinopathy was assessed by centrally graded retinal photography. Autonomic neuropathy was measured by heart rate and blood pressure responses to standing up. Sensory neuropathy was measured by biothesiometry. Normal $\mathrm{HbA}_{1 \mathrm{c}}$ was found in $16 \%$ of patients. An AER of $20 \mu \mathrm{g} / \mathrm{min}$ or higher was found in $30.6 \%$ $(95 \%$ CI $29.0 \%, 32.2 \%)$ of all patients, and $19.3 \%$ $(15.6 \%, 23.0 \%)$ of those with diabetes for 1 to 5 years. The prevalence of retinopathy $(46 \%$ in all patients;
$82 \%$ after 20 or more years) was substantially lower than in comparable studies. Of all patients $5.9 \%$ $(5.1 \%, 6.7 \%)$ had postural hypotension, $19.3 \%$ $(17.9 \%, 20.7 \%)$ had abnormal heart rate variability, $32.2 \%(30.6 \%, 33.8 \%)$ reported one or more severe hypoglycaemic attacks during the last 12 months and $8.6 \%(7.6 \%, 9.6 \%)$ reported hospital admission for ketosis over the same period. Microvascular and acute complications were clearly related to duration of diabetes and to glycaemic control. However, the relation of glycaemic control to raised albuminuria differed qualitatively from its relation to retinopathy. [Diabetologia (1994) 37: 278-285]

Key words IDDM, glycaemic control, hypoglycaemia, ketosis, retinopathy, nephropathy, neuropathy.
Insulin-dependent diabetes mellitus (IDDM) is becoming more common in Europe [1] and few patients escape its complications which are a major cause of morbidity and premature death [2]. The EURODIAB IDDM Complications Study is a cross-sectional clinicbased study of complications in 3250 randomly-se-

\footnotetext{
* see Acknowledgements for complete list of participating hospitals and clinics
}

Received: 27 April 1993

and in final revised form: 21 September 1993

Corresponding author: Dr. J.H.Fuller, Department of Epidemiology and Public Health, University College London, 66-72 Gower St., London WC1 E 6EA, UK

Abbreviations: IDDM, Insulin-dependent diabetes mellitus; VPT, vibration perception threshold; AER, rate of urinary albumin excretion; CI, confidence interval. lected IDDM patients attending 31 clinics in 16 European countries. It was established to measure the prevalence and severity of diabetic complications and to examine specific relations between putative risk factors and complications. This report describes the prevalence of microvascular disease (nephropathy, retinopathy and neuropathy) and acute metabolic complications (severe hypoglycaemia and ketosis), and provides new insight into their relation with the major risk factors, duration of diabetes and glycaemic control [3-5].

\section{Subjects, materials and methods}

IDDM was defined as diabetes diagnosed before the age of 36 years with continuous need for insulin 1 year after diagnosis. At each centre (except Cagliari and Dusseldorf Medizinische Klinik E), a stratified random sample of up to 140 (see below) patients aged 15-60 years was selected from a sampling frame of all IDDM patients who had attended the diabetes clinic, or re- 
Table 1. Age, duration of diabetes and $\mathrm{HbA}_{1 \mathrm{c}}$ by centre

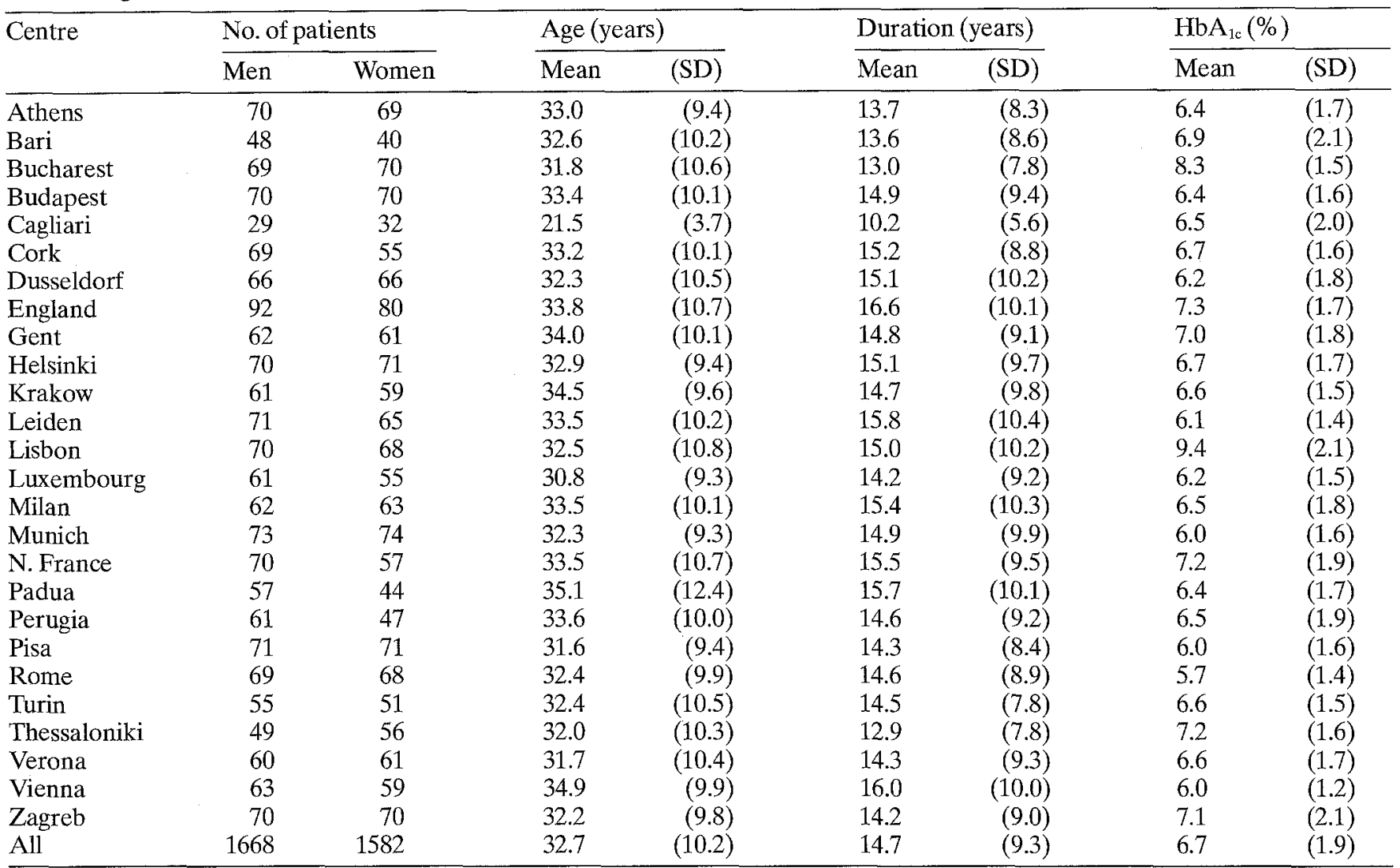

lated clinics such as a renal clinic, at least once during the previous 12 months. Patients were stratified by sex, age in three groups (15-29, 30-44 and 45-60 years) and duration in three groups (1-7, 8-14 and $15+$ years) before randomly selecting 10 patients from each stratum. Stratification determined a similar distribution of age and duration within, and men and women in each centre (Table 1). In Cagliari, all clinic attenders were aged below 30 years; these patients were stratified according to sex and duration as above before random selection. In Dusseldorf Medizinische Klinik E, patients were selected consecutively, not randomly. In Northern France (Valenciennes and Paris) and in Dusseldorf, recruitment was shared by two independent centres; data from each of the two centres have been combined in this report. Data from four English centres (NW London, Sheffield, Wolverhampton and Manchester) have been combined as one centre. At each centre, informed consent from all patients and ethical committee approval for the study was obtained. Pregnant women, patients who were unrepresentative of local ethnic groups and those with IDDM for less than 1 year were not recruited into the study. Patients were invited to participate in the study in person, by phone and by letter. Fourteen percent of eligible patients could not be contacted. Of the remainder who responded to the invitation, $85 \%$ took part in the study, giving an overall response rate of $73 \%$ and a total of 3250 participants (51\% male). Their mean (SD) age was 32.7 (10.7) years and duration of diabetes was 14.7 (9.3) years. Most centres investigated between 120 and 140 patients (Table 1 ).

After attending regional training sessions, investigators followed standard procedures described in a comprehensive manual of operations (available on request). Severe hypoglycaemia was defined as any episode severe enough to require the help of another person. Severe ketosis was defined as an episode requir- ing hospital admission. Patients were asked how many such episodes they had had over the last 12 months.

Sensory neuropathy was measured by VPT using centrally calibrated biothesiometers. VPT was measured with the biothesiometer resting horizontally on the tip of the right great toe and the mean of three readings used for analysis. Autonomic neuropathy was measured by testing two cardiovascular reflex responses: change in heart rate and change in systolic blood pressure on standing upright after resting horizontally for at least $5 \mathrm{~min}$. A single observer calculated the postural change in ECG-recorded heart rate as the ratio of the longest beat-to-beat ( $R-R$ interval between QRS complexes) interval between the 28 th and 32 nd beats to the shortest beat-beat interval between the 13 th and 17 th beats (R-R ratio). Beats were counted from the time at which the patient started to stand up. Blood pressure was measured once in the horizontal position, and once again, 60 s after standing upright. Both measurements were made to the nearest $2 \mathrm{~mm} \mathrm{Hg}$ using a Hawksley random zero sphygmomanometer.

All but two centres (Bucharest and Krakow) took retinal diapositives with a wide angle camera after pupil dilation. Two precisely defined fields (disc-macula-temporal and disc-nasal) were photographed in each eye, using Kodachrome 64 ASA diapositive film. A single observer graded all retinal diapositives by comparing them with standard diapositives taken with a $45^{\circ}$ camera and chosen to illustrate lesions of different severity. Each patient's level of retinopathy was determined by the worse eye. In this report, retinopathy is classified as background or proliferative. Proliferative retinopathy was defined as any new vessels, fibrous proliferations, pre-retinal haemorrhage, vitreous haemorrhage or photocoagulation scars.

Focus, clarity and field definition were adequate for grading in $91 \%$ of all retinal fields received. All patients with at least one 
Table 2. Sensory and autonomic tests and acute complications by duration and glycaemic control

\begin{tabular}{|c|c|c|c|c|c|c|c|c|c|c|c|c|}
\hline \multirow{3}{*}{$\begin{array}{l}\text { Duration } \\
\text { quartiles } \\
\text { (years) }\end{array}$} & \multicolumn{2}{|c|}{$\begin{array}{l}\text { VPT at great toe } \\
\text { (volts) }\end{array}$} & \multicolumn{2}{|c|}{$\begin{array}{l}\text { Fall in systolic BP } \\
\text { on standing }(\mathrm{mm} \mathrm{Hg})\end{array}$} & \multicolumn{2}{|c|}{$\begin{array}{l}\text { Heart rate variability } \\
\text { (max/min R-R interval) }\end{array}$} & \multicolumn{3}{|c|}{$\begin{array}{l}\text { Proportion of patients with } \\
\geq 1 \text { severe hypoglycaemic } \\
\text { attack in last } 12 \text { months }\end{array}$} & \multicolumn{3}{|c|}{$\begin{array}{l}\text { Proportion of patients } \\
\text { with } \geq 1 \text { admission for } \\
\text { ketosis in last } 12 \text { months }\end{array}$} \\
\hline & \multirow{2}{*}{$\begin{array}{l}\text { Crude } \\
\text { median }\end{array}$} & \multirow{2}{*}{$\begin{array}{l}\text { Adjusted }^{a} \\
\text { median } \\
(95 \% \mathrm{CI})\end{array}$} & \multirow{2}{*}{$\begin{array}{l}\text { Crude } \\
\text { mean }\end{array}$} & \multirow{2}{*}{$\begin{array}{l}\text { Adjusted } \\
\text { mean } \\
(95 \% \mathrm{CI})\end{array}$} & \multirow{2}{*}{$\begin{array}{l}\text { Crude } \\
\text { median }\end{array}$} & \multirow{2}{*}{$\begin{array}{l}\text { Adjusted } \\
\text { median } \\
(95 \% \mathrm{CI})\end{array}$} & \multirow{2}{*}{$\frac{\text { Crude }}{\%}$} & \multicolumn{2}{|c|}{ Adjusted } & \multirow{2}{*}{$\frac{\text { Crude }}{\%}$} & \multicolumn{2}{|c|}{ Adjusted } \\
\hline & & & & & & & & $\%$ & $(95 \% \mathrm{CI})$ & & $\%$ & $(95 \% \mathrm{CI})$ \\
\hline$\overline{1-}$ & 5 & $5(4,6)$ & 2.0 & $2.7(1.1,4.3)$ & 1.25 & $1.22(1.14,1.28)$ & 21.9 & 20.2 & $(17.0,23.4)$ & 11.5 & 11.6 & $\overline{(9.2,14.0)}$ \\
\hline $7-$ & 6 & $6(6,6)$ & 3.1 & $3.4(1.9,4.9)$ & 1.21 & $1.20(1.18,1.24)$ & 30.6 & 30.0 & $(27.8,32.2)$ & 8.7 & 8.2 & $(6.9,9.5)$ \\
\hline \multicolumn{13}{|c|}{$H b A_{1 \mathrm{c}}$ quartiles (\%) } \\
\hline$<5.4$ & 6 & $6(5,6)$ & 2.3 & $2.3(0.8,3.8)$ & 1.22 & $1.21(1.18,1.26)$ & 40.1 & 41.5 & $(39.0,44.0)$ & 4.7 & 4. & $(3.6,5.8)$ \\
\hline $5.4-$ & 6 & $6(6,7)$ & 3.2 & $2.9(1.5,4.4)$ & 1.18 & $1.18(1.15,1.21)$ & 34.6 & 34.1 & $(31.9,36.4)$ & 6.2 & 6.1 & $(4.9,6.1)$ \\
\hline 6.5 & 7 & $7(6,7)$ & 5.3 & $5.2(3.7,6.7)$ & 1.15 & $1.16(1.14,1.19)$ & 30.3 & 29.8 & $(2.7,31.9)$ & 7.5 & 7.9 & $(6.6,9.2)$ \\
\hline $7.8+$ & 7 & $7(7,8)$ & 5.0 & $5.3(3.9,6.8)$ & 1.13 & $1.12(1.10,1.14)$ & 24.3 & 25.8 & $(23.7,27.9)$ & 15.9 & 15.4 & $(13.7,17.1)$ \\
\hline
\end{tabular}

${ }^{a}$ Means, medians and proportions by duration adjusted for age and $\mathrm{HbA}_{1 \mathrm{c}}$;

Means, medians and proportions by $\mathrm{HbA}_{1 \mathrm{c}}$ adjusted for age and duration

graded field $(n=2479)$ have been included because exclusion of patients with incomplete grading would have led to underestimation of patients with more severe retinopathy. A more rigorous protocol [6] requiring stereophotographs of seven retinal fields was followed in 26 patients in addition to the study protocol. With both protocols, the same three patients were graded as having no retinopathy, and all remaining patients were graded as having retinopathy. There was therefore complete agreement between the two protocols on the presence or absence of any retinopathy.

The AER was calculated from a timed 24 -h urine collection, after excluding proteinuria due to urinary tract infection. Urinary albumin was measured in a single laboratory by an immunoturbidimetric method [7] using goat anti-human albumin antisera (Sanofi Diagnostics Pasteur Inc., Minn., USA) and human serum albumin standards (ORHA 20/21 grade HSA; Behring Diagnostics, Hoechst UK Ltd, Hounslow, Middlesex, UK). AER was defined as normal below $20 \mu \mathrm{g} / \mathrm{min}$ and raised at or above this level. Microalbuminuria was defined as AER above $20 \mu \mathrm{g} / \mathrm{min}$ and less than $200 \mu \mathrm{g} / \mathrm{min}$, and macroalbuminuria as AER at or above $200 \mu \mathrm{g} / \mathrm{min}$. Hidden duplicate samples of urine were obtained from a $10 \%$ random subsample of patients. The coefficient of reliability [1-(within person variance of the difference between repeated measurements/between person variance of a single measurement)] gives a measure of the relative magnitude of measurement error to between person variability. The coefficient of reliability for urinary albumin concentration in this study was high $(0.97)$.

$\mathrm{HbA}_{1 \mathrm{c}}$ (normal range $2.9 \%-4.8 \%$ ) was measured in a central laboratory by an enzyme immunoassay [8] using a monoclonal antibody raised against $\mathrm{HbA}_{1 \mathrm{c}}$ (Dako Ltd, Ely, UK).

\section{Statistical analysis}

The independent relation of duration of diabetes and $\mathrm{HbA}_{1 \mathrm{c}}$ to diabetic complications was examined by adjusting each exposure for the effect of the other. The importance of age as an independent confounder was examined separately for each complication before inclusion in the final estimate. In two of the figures ( 3 and 5), the prevalence of albuminuria and retinopathy was directly standardised to the distribution of duration of diabetes in the whole sample, with duration in 5-year intervals.

In Table 2, prevalences (severe hypoglycaemia and ketosis) and medians (VPT and R-R ratio) by $\mathrm{HbA}_{1 c}$ quartiles were directly standardised to the distribution of age and duration in the whole sample. Prevalences and medians by duration quartiles were directly standardised to the distribution of age and $\mathrm{HbA}_{1 \mathrm{c}}$ in the whole sample. Mean postural change in systolic blood pressure was adjusted for age and diabetes duration, and for age and $\mathrm{HbA}_{1 \mathrm{c}}$, using least-squares regression models. The adjusted means are the values predicted in the model when the other variables are held at their mean values. Tests of significance for proportions were based on the Cochran-Mantel-Haenszel chisquare statistic.

\section{Results}

\section{Prevalence of complications and relation to duration of diabetes}

Microalbuminuria was found in $20.7 \%$ (95\% CI $19.3 \%, 22.1 \%$ ) of patients and macroalbuminuria in $8.8 \%(7.8 \%, 9.8 \%)$. Raised AER was more common in men $(33.1 \%)$ than women $(26.6 \%, p=0.001)$. The prevalence of macroalbuminuria rose steeply between 5 and 20 years duration of diabetes and then declined, but the prevalence of microalbuminuria was relatively constant, ranging from $18 \%$ to $25 \%$ at 5 -year intervals (Fig.1). Of patients with diabetes duration between 1 and 5 years, $19 \%(16 \%, 23 \%)$ had albumin excretion at or above $20 \mu \mathrm{g} / \mathrm{min}$.

Background retinopathy was found in $35.9 \%$ $(34.0 \%, 37.8 \%)$ of patients, and proliferative retinopathy in $10.3 \%(9.1 \%, 11.5 \%)$, with no significant difference $(p=0.12)$ in the frequency of any retinopathy between men and women. The prevalence of background retinopathy increased most steeply between 5 and 15 years duration and reached a plateau of $82 \%$ $(79 \%, 85 \%)$ after 20 years (Fig. 2$)$. Proliferative retinopathy was virtually absent before 10 years, after which it rose steadily to reach a prevalence of $37 \%$ $(29 \%, 44 \%)$ after 30 or more years of diabetes.

Median VPT was 6 volts (3-27 volts). Using Ewing's definitions [9] of postural hypotension (fall in systolic pressure of $30 \mathrm{~mm} \mathrm{Hg}$ or more) and loss of heart rate 


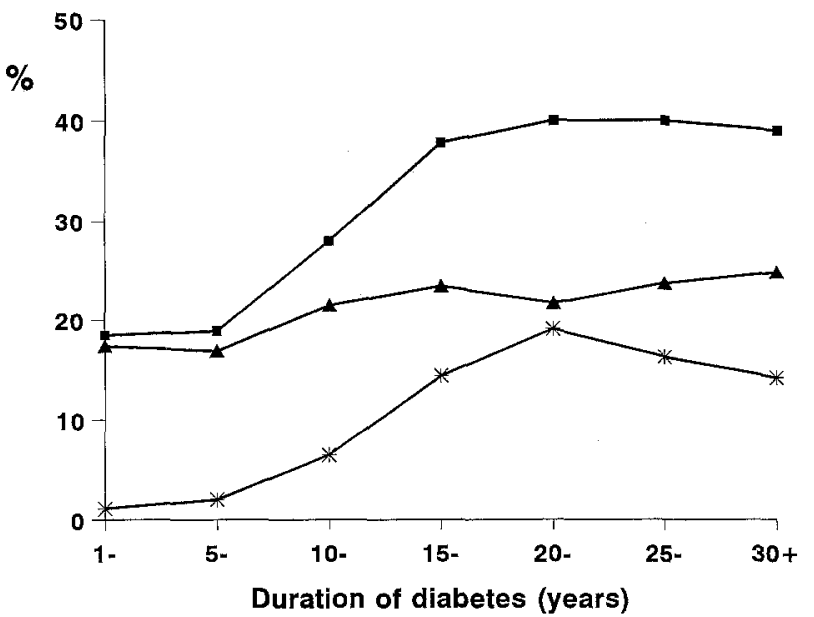

Fig. 1. Prevalence of albuminuria by duration of diabetes. Macroalbuminuria $(*)$, microalbuminuria $(\boldsymbol{\Delta})$ and microalbuminuria or macroalbuminuria ( $\boldsymbol{a})$. The top curve is the sum of the lower two

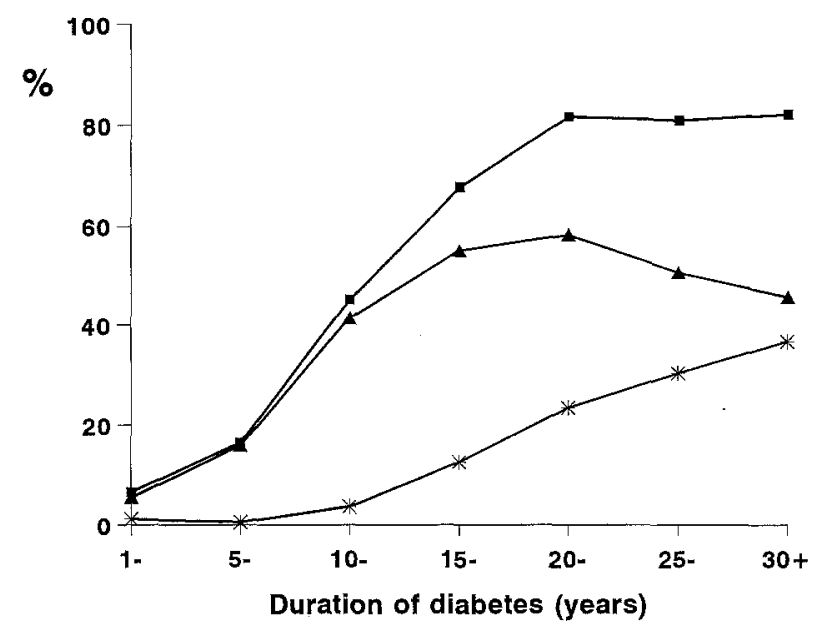

Fig. 2. Prevalence of retinopathy by duration of diabetes. Proliferative retinopathy $(*)$, background retinopathy ( $\mathbf{\Delta})$ and any retinopathy ( $)$. The top curve is the sum of the lower two

Table 3. Frequency of microvascular and acute complications by centre

\begin{tabular}{|c|c|c|c|c|c|c|c|c|c|c|c|c|c|c|}
\hline \multirow[t]{2}{*}{ Centre } & \multicolumn{2}{|c|}{$\begin{array}{l}\mathrm{AER} \geq 20 \mu \mathrm{g} / \\
\min \end{array}$} & \multicolumn{2}{|c|}{ Retinopathy } & \multicolumn{2}{|c|}{$\begin{array}{l}\text { Proportion of } \\
\text { patients with } \\
\geq 1 \text { severe hypo- } \\
\text { glycaemic attack } \\
\text { in } 12 \text { months }\end{array}$} & \multicolumn{2}{|c|}{$\begin{array}{l}\text { Proportion of } \\
\text { patients with } \geq 1 \\
\text { admission for } \\
\text { ketosis in last } \\
12 \text { months }\end{array}$} & \multicolumn{2}{|c|}{$\begin{array}{l}\text { VPT at great toe } \\
\text { (volts) }\end{array}$} & \multicolumn{2}{|c|}{$\begin{array}{l}\text { Postural hypo- } \\
\text { tension }\end{array}$} & \multicolumn{2}{|c|}{$\begin{array}{l}\text { Loss of heart } \\
\text { rate variability }\end{array}$} \\
\hline & $\%$ & $(95 \% \mathrm{CI})$ & $\%$ & $(95 \% \mathrm{CI})$ & $\%$ & $(95 \% \mathrm{CI})$ & $\%$ & $(95 \% \mathrm{CI})$ & median & $(95 \% \mathrm{CI})$ & $\%$ & $(95 \% \mathrm{CI})$ & $\%$ & $(95 \% \mathrm{CI})$ \\
\hline Athens & 23 & $(16,30)$ & 42 & $(36,50)$ & 46 & $(38,54)$ & 2.2 & $(0.5,6.3)$ & 8 & $(4,25)$ & 4.4 & $(1.0,7.8)$ & 24.4 & $(16.7,32.1)$ \\
\hline Bari & 32 & $(22,42)$ & 37 & $(25,49)$ & 33 & $(23,43)$ & 10.2 & $(3.9,16.5)$ & 5 & $(2,22)$ & 4.6 & $(1.2,11.6)$ & 24.4 & $(15.3,33.5)$ \\
\hline Cagliari & 27 & $(16,38)$ & 38 & $(25,51)$ & 15 & $(6,24)$ & 3.3 & $(0.4,11.8)$ & 4 & $(2,9)$ & 4.9 & $(1.0,14.4)$ & 40.7 & $(28.2,53.2)$ \\
\hline Cork & 30 & $(22,38)$ & 53 & $(43,63)$ & 45 & $(36,54)$ & 0.8 & $(0.02,4.5)$ & 7 & $(4,29)$ & 2.5 & $(0.5,7.3)$ & 7.8 & $(2.9,12.7)$ \\
\hline Dusseldorf & 32 & $(23,41)$ & 51 & $(40,62)$ & 34 & $(26,42)$ & 9.1 & $(4.2,14.0)$ & 7 & $(2,23)$ & 7.6 & $(3.1,12.1)$ & 15.2 & $(8.6,21.9)$ \\
\hline England & 27 & $(20,34)$ & 51 & $(43,60)$ & 34 & $(27,41)$ & 8.1 & $(4.4,13.7)$ & 7 & $(3,26)$ & 4.1 & $(1.1,7.1)$ & 11.8 & $(6.7,16.9)$ \\
\hline Gent & 38 & $(32,44)$ & 47 & $(37,57)$ & 12 & $(6,18)$ & 3.3 & $(0.9,8.3)$ & 7 & $(4,29)$ & 2.4 & $(0.5,7.3)$ & 29.3 & $(21.0,37.6)$ \\
\hline Helsinki & 39 & $(31,47)$ & 54 & $(46,62)$ & 26 & $(19,33)$ & 3.6 & $(1.2,8.3)$ & 6 & $(3,26)$ & 12.1 & $(6.7,17.5)$ & 22.5 & $(15.5,29.5)$ \\
\hline Milan & 21 & $(13,29)$ & 46 & $(37,55)$ & 20 & $(13,27)$ & 4.8 & $(1.1,8.6)$ & 8 & $(3,31)$ & 9.1 & $(4.0,14.2)$ & 8.6 & $(3.5,13.7)$ \\
\hline Munich & 26 & $(19,33)$ & 48 & $(40,56)$ & 42 & $(34,50)$ & 9.5 & $(4.8,14.2)$ & 6 & $(2,17)$ & 2.0 & $(0.4,6.0)$ & 10.3 & $(5.4,15.2)$ \\
\hline N. France & 33 & $(24,42)$ & 35 & $(25,45)$ & 21 & $(14,28)$ & 4.7 & $(1.0,8.4)$ & 6 & $(3,31)$ & 2.4 & $(0.5,6.9)$ & 22.1 & $(14.1,30.1)$ \\
\hline Padua & 31 & $(22,40)$ & 44 & $(34,54)$ & 26 & $(17,35)$ & 8.9 & $(3.4,14.5)$ & 10 & $(4,30)$ & 4.0 & $(1.1,10.1)$ & 15.4 & $(8.0,22.8)$ \\
\hline Perugia & 22 & $(14,30)$ & 35 & $(25,45)$ & 19 & $(12,26)$ & 9.3 & $(3.8,14.8)$ & 5 & $(3,50)$ & 0 & & 7.8 & $(2.6,13.0)$ \\
\hline Pisa & 22 & $(15,29)$ & 37 & $(28,46)$ & 39 & $(31,47)$ & 2.1 & $(0.4,6.2)$ & 5 & $(2,15)$ & 2.8 & $(0.8,7.2)$ & 15.6 & $(9.5,21.7)$ \\
\hline Rome & 24 & $(17,31)$ & 48 & $(39,57)$ & 37 & $(29,45)$ & 3.7 & $(0.5,6.9)$ & 5 & $(2,23)$ & 10.2 & $(5.1,15.3)$ & 23.2 & $(15.4,31.0)$ \\
\hline Turin & 32 & $(23,41)$ & 34 & $(22,46)$ & 23 & $(15,31)$ & 3.8 & $(1.0,9.7)$ & 6 & $(2,20)$ & 4.9 & $(1.6,11.3)$ & 15.5 & $(8.5,22.5)$ \\
\hline Thessaloniki & 39 & $(29,49)$ & 53 & $(43,63)$ & 38 & $(29,47)$ & 14.3 & $(7.6,21.0)$ & 7 & $(4,17)$ & 4.8 & $(1.5,11.1)$ & 16.2 & $(8.9,23.5)$ \\
\hline Verona & 28 & $(20,36)$ & 41 & $(32,50)$ & 26 & $(18,34)$ & 5.8 & $(1.6,10.0)$ & 6 & $(3,15)$ & 10.7 & $(5.2,16.2)$ & 9.0 & $(3.7,14.3)$ \\
\hline Vienna & 27 & $(19,35)$ & 25 & $(17,33)$ & 23 & $(16,31)$ & 7.4 & $(2.8,12.1)$ & 8 & $(4,19)$ & 4.9 & $(1.1,8.7)$ & 12.1 & $(6.2,18.0)$ \\
\hline Zagreb & 45 & $(37,53)$ & 59 & $(51,67)$ & 34 & $(26,42)$ & 7.1 & $(2.9,11.4)$ & 8 & $(4,44)$ & 10.7 & $(5.6,15.8)$ & 23.5 & $(16.3,30.7)$ \\
\hline All & 31 & $(29,32)$ & 46 & $(44,48)$ & 32 & $(31,34)$ & 8.6 & $(7.6,9.6)$ & 6 & $(3,27)$ & 5.9 & $(5.1,6.7)$ & 19.3 & $(17.9,20.7)$ \\
\hline
\end{tabular}

variability ( $\mathrm{R}-\mathrm{R}$ ratio $\leq 1.0$ ), the prevalence of abnormal autonomic reflexes was $5.9 \%(5.1 \%, 6.7 \%)$ and $19.3 \%(17.9 \%, 20.7 \%)$ respectively. All three neuropathic tests were clearly related to the duration of diabetes (Table 2).
The proportion of patients reporting one or more severe hypoglycaemic attacks in the previous 12 months was $32.2 \%(30.6 \%, 33.8 \%)$ and the proportion reporting one or more hospital admissions for ketoacidosis during the same period was $8.6 \%(7.6 \%$, 


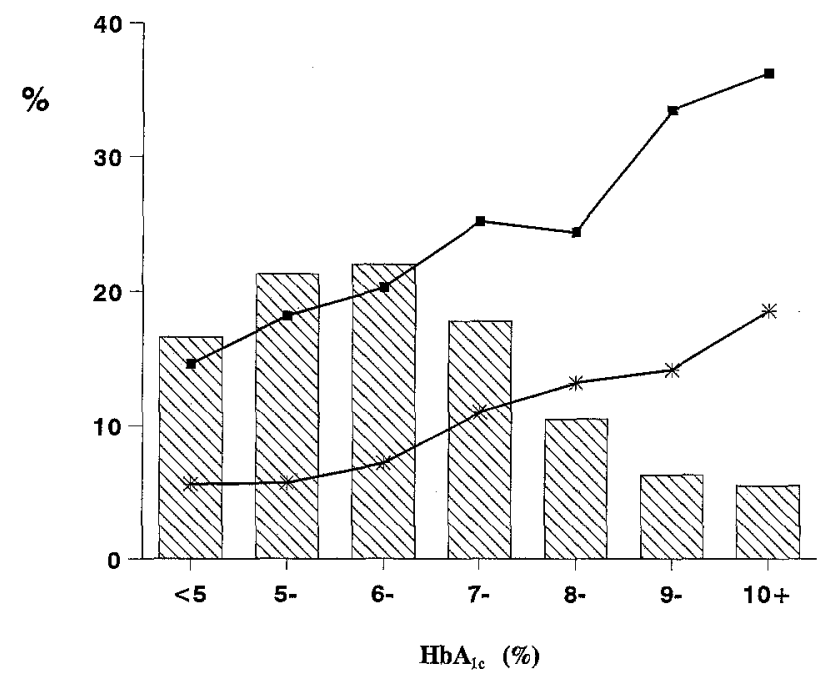

Fig. 3. Prevalence of microalbuminuria ( $\boldsymbol{a})$ and macroalbuminuria (*) by $\mathrm{HbA}_{1 \mathrm{c}}$. Prevalence is adjusted for duration of diabetes

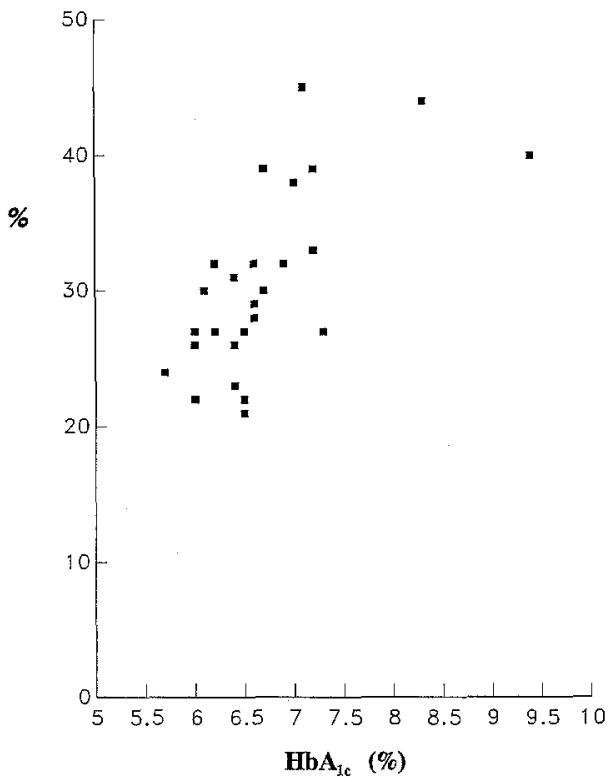

Fig. 4. Prevalence of raised albuminuria ( $\geq 20 \mu \mathrm{g} / \mathrm{min}$ ) by mean $\mathrm{HbA}_{1 \mathrm{c}}$ in each centre

$9.6 \%$ ). Severe hypoglycaemia, but not ketosis, was clearly related to duration of diabetes (Table 2). The prevalence of microvascular and acute metabolic complications by centre is shown in Table 3 .

\section{Relation between complications and glycaemic control}

Sixteen percent of patients had $\mathrm{HbA}_{1 \mathrm{c}}$ within the normal, non-diabetic range $(2.9-4.8 \%)$. In these patients, the prevalence of microalbuminuria was $14.3 \%$ $(11.2 \%, 17.5 \%)$ and the prevalence of macroalbuminuria $4.7 \%(2.8 \%, 6.6 \%)$. Corresponding figures for background and proliferative retinopathy were

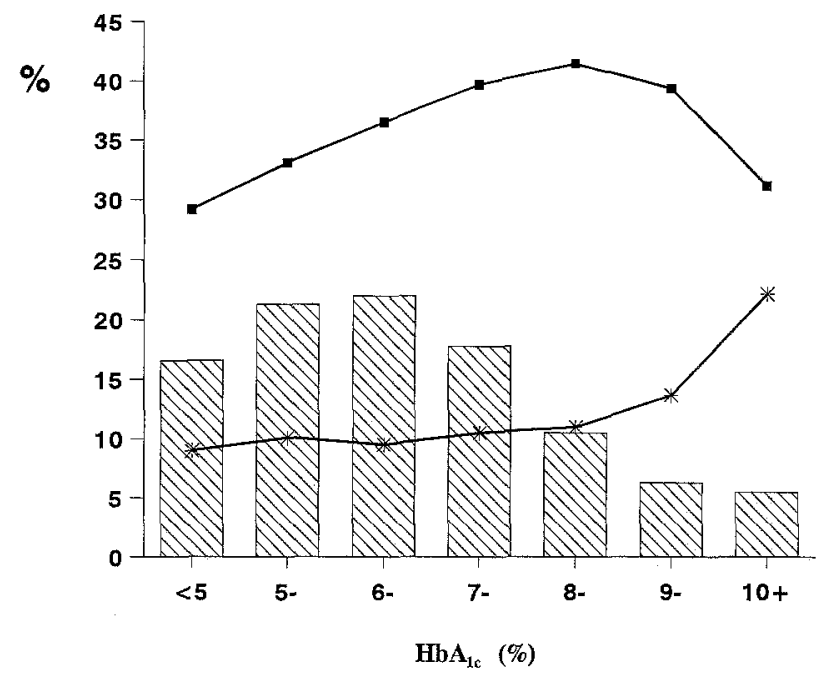

Fig.5. Prevalence of background ( $\mathbf{m})$ and proliferative $\left({ }^{*}\right)$ retinopathy by $\mathrm{HbA}_{1 \mathrm{c}}$. Prevalence is adjusted for duration of diabetes

$25.6 \%(21.5 \%, 29.8 \%)$ and $7.9 \%(5.4 \%, 10.5 \%)$, and the proportion of patients reporting at least one severe hypoglycaemic attack during the last 12 months was $38.6 \%(34.4 \%, 42.9 \%)$. A clear increase in frequency of raised albuminuria with $\mathrm{HbA}_{1 \mathrm{c}}$ was observed at both the individual (Fig. 3) and centre level (Fig. 4). The relation between $\mathrm{HbA}_{1 \mathrm{c}}$ and frequency of albuminuria was similar when analysed separately for micro- and macroalbuminuria (Fig. 3). By contrast, the relation of $\mathrm{HbA}_{1 \mathrm{c}}$ to background retinopathy was quite different to that of proliferative retinopathy (Fig.5). Below an $\mathrm{HbA}_{1 \mathrm{c}}$ concentration of $8 \%$, the prevalence of background retinopathy increased significantly with $\mathrm{HbA}_{1 \mathrm{c}}$, while the frequency of proliferative retinopathy was fairly constant. Above an $\mathrm{HbA}_{1 \mathrm{c}}$ level of $8 \%$, the prevalence of proliferative retinopathy began to rise as the increase in frequency of background retinopathy reversed. Both autonomic tests, VPT and severe hypoglycaemia and ketosis were clearly related to $\mathrm{HbA}_{1 \mathrm{c}}$ (Table 2).

\section{Discussion}

The EURODIAB IDDM Complications Study is one of the largest clinic-based studies of its kind combining standardised methods with central measurement of important outcomes. The study was clinic, rather than population, based because population-based sampling frames from which IDDM patients can be identified and recruited for study are rare. What, then, is the likely impact of selection bias on our findings? Clinic-based estimates of the regional prevalence of complications will be biased if clinic-attenders have more or fewer complications than the population of IDDM patients from which the attenders are drawn. While some patients may be referred to clinics because of advanced 
complications, others' motivation to attend may be associated with better control and fewer complications than in non-attenders [10]. Individual clinics may therefore over- or underestimate the regional prevalence of complications, depending on the balance between these opposing biases.

Selection bias is less likely to affect associations between risk factors (exposures) and complications (outcomes). For example, clinic-attenders may have longer (or shorter) duration of diabetes, and a higher (or lower) prevalence of retinopathy than non-attenders, but it is unlikely that the relation between duration of diabetes and retinopathy differs importantly between those who attend clinics and those who do not. In general, although factors determining clinic attendance are poorly defined and difficult to measure, they need not bias the association between risk factors and complications, providing the selective forces for exposure and outcome are independent of each other. The strength of the EURODIAB Complications Study therefore lies in elucidating the relation between specific outcomes and exposures. The study also provides information about the burden of complications and risk factors encountered in diabetic clinics across $\mathrm{Eu}-$ rope. Since factors determining clinic referral may vary by region, differences between centres in the prevalence of complications are hard to interpret unless they can be explained in relation to risk factors that demonstrate the same effect at the level of the individual (as shown for the relation between glycaemic control and albuminuria).

The relation between duration and prevalence of retinopathy is similar to that described in two American population-based studies in Wisconsin [11] and Pittsburgh [12] confirming a rapid rise in the prevalence of retinopathy between 5 and 15 years and virtually no proliferative retinopathy before 10 years. These similarities support the premise that complications in clinic attenders do not develop in a way unlike that of the wider population of IDDM patients. Absolute prevalences, however, were lower in this study, with $82 \%$ of patients having retinopathy after 20 years, compared with almost $100 \%$ in the American studies. The prevalence of proliferative changes after 30 years of diabetes was $36 \%$ in this study and $60 \%$ [11] to $75 \%$ [12] in the American studies. Our comparison of the EURODIAB two-field method with the more extensive protocol used in the American studies indicates that method differences alone are unlikely to account for the lower prevalence of any retinopathy in this study. An alternative explanation is better glycaemic control: $6.7 \%$ [11] and 1\% (T. Orchard, personal communication) of study subjects in the American studies had glycated haemoglobin in the non-diabetic range, compared with $16 \%$ in the present study. This explanation assumes a causal relation between glycaemic control and retinopathy which cannot be adressed adequately by observational studies. The crucial question of whether, or to what extent, improved control prevents the incidence or progression of retinopathy has been examined most recently in a definitive randomised controlled trial of strict vs conventional control (The Diabetes Control and Complications Trial, DCCT [13]). The trial has examined both primary and secondary prevention of complications in a highly select group of well-motivated IDDM patients. The first presentation of the DCCT results (American Diabetes Association meeting, June 1993, Las Vegas, Nev., USA) showed that strict control substantially reduces the risk of long-term complications, particularly retinopathy. Previously published results [14] have shown that strict control also causes a three- to four-fold increase in the risk of severe hypoglycaemia - an effect reflected in our prevalence data. As the full findings of the DCCT become widely publicised, informed individuals will be able to weigh the measured benefits against the risks of strict control. For those delivering diabetes care, one of the key issues will be the extent to which the findings of this trial can be applied to the wider population of IDDM patients.

The possibility of a glycaemic threshold for retinopathy has aroused much interest [15]. Although it is difficult to draw firm conclusions from cross-sectional data, we found a decline in frequency of background retinopathy and coincident rise in proliferative retinopathy at $\mathrm{HbA}_{1 \mathrm{c}}$ above $8 \%$ which might indicate a threshold effect with important implications for avoidance of sight-threatening retinopathy. Prospective studies $[15,16]$ including the DCCT have shown a particularly strong relation between glycated haemoglobin and proliferative retinopathy, but have not reported a clear glycaemic threshold. Whether or not such a threshold exists, it is clear from our data that the relation of glycaemic control to raised albuminuria differs qualitatively from its relation to retinopathy. Unlike retinopathy, the rise in frequency of macroalbuminuria with $\mathrm{HbA}_{1 \mathrm{c}}$ was not accompanied by any coincident fall in microalbuminuria and there was no indication of a threshold effect. Qualitative differences in the relation of glycaemic control to retinopathy and albuminuria have not been described before. Independent examination in other large observational studies would be helpful.

In assessing the importance of glycaemic control in an observational study, it is important to note that the true relation between glycaemic control and diabetic complications will be stronger than is apparent in this study. This is partly because patients who know they have complications are more likely to improve than to worsen their control as a consequence of this knowledge, and partly because a single measure of $\mathrm{HbA}_{1 \mathrm{c}}$ is an imprecise estimate of an individual's usual glycaemic control. The effect of such measurement imprecision is to weaken or dilute the relation between $\mathrm{HbA}_{1 \mathrm{c}}$ and diabetic complications [17].

Another possible explanation for the comparatively low frequency of proliferative retinopathy in this study 
might be greater use of retinal photocoagulation. Differences in use of photocoagulation are difficult to compare between these studies, but fewer than $2 \%$ of patients in Wisconsin [11] compared with $6.4 \%$ of EURODIAB patients had signs of photocoagulation with no proliferative lesions, indicating successful treatment of proliferative retinopathy.

The relation between duration and prevalence of macroalbuminuria accords with other studies which have shown a fall in the incidence of nephropathy after 20 years of diabetes $[18,19]$. By contrast, the prevalence of microalbuminuria varied little with duration and did not fall appreciably after 20 years, suggesting that progression to macroalbuminuria may not be the rule, at least in patients with long-term diabetes. This conclusion is supported by a recent prospective study of microalbuminuric patients with IDDM for more than 15 years [20] in which only 5 ( $28 \%$ ) of 18 patients progressed to macroalbuminuria during a 10 year follow-up. Raised albuminuria of diabetic origin is thought to be rare before 5 years of IDDM, but we found an AER of $20 \mu \mathrm{g} / \mathrm{min}$ or more in $19 \%$ of patients with diabetes duration between 1 and 5 years. Part of the explanation for this lies in differences in the method of urine collection and definition of raised albumin excretion: in order to compare our results with a study in which urine is collected overnight (when albumin excretion may be $25 \%$ lower than by day) and raised albumin excretion defined as greater than $30 \mu \mathrm{g} / \mathrm{min}$, we need to examine the frequency of albumin excretion above $40 \mu \mathrm{g} / \mathrm{min}$, which was $9 \%$ (95\% CI $6 \%$ to $12 \%$ ) in patients with diabetes duration between 1 and 5 years. Raised albuminuria in patients of short duration was found in all centres. Control was poorer in microalbuminuric patients than those with normal AER, but mean $\mathrm{HbA}_{1 \mathrm{c}}$ did not differ between microalbuminuric patients with duration of 1 to 5 years and microalbuminuric patients with diabetes for 6 years or more. Previous prevalence studies might have missed early duration albuminuria simply because they investigated few patients, while larger, more recent studies $[12,21]$ have apparently not looked for albuminuria in people with IDDM for less than 5 years. Although we cannot completely exclude selection bias as an explanation for our finding, previous detection of microalbuminuria in these patients leading to clinic referral seems unlikely. Careful follow-up of patients with early albuminuria is needed to determine its clinical significance and rate of progression to proteinuria.

In the absence of a precise agreed definition of diabetic neuropathy, comparison of the prevalence of the condition between different epidemiological studies is difficult, although most definitions based on clinical features are similar [22]. Our data confirms the association of diabetic polyneuropathy with age and duration of diabetes [23], and highlights a strong relation with glycaemic control independent of diabetes duration. As in other reports, the prevalence of abnor- mal autonomic function increased with diabetes duration and glycated haemoglobin [24].

In summary, we have found microalbuminuria in a significant proportion of patients with IDDM for less than 5 years and qualitative differences in the relation of glycaemic control to retinopathy and albuminuria which have not been reported before.

Acknowledgements. The participation of all the patients in the study is gratefully acknowledged. The study was part of the EURODIAB Concerted Action Programme financially supported by the Commission of the European Communities. Additional financial support from ICI UK, Fidia, Bayer, Miles-Ames, Novo Nordisk and Pfizer is gratefully acknowledged.

\section{EURODIAB Investigators}

B Karamanos, CTountas, A Kofinis, K Petrou, N Katsilambros, Hippokration Hospital, Athens, Greece.

M Cignarelli, R Giorgino, M Cignarelli, ML De Geco, I Ramunni, Cattedra di Endocrinologia - Policlinico, Bari, Italy.

C Ionescu-Tirgoviste, CM Iosif, D Pitei, S Buligescu, Clinic of Diabetes, Nutrition \& Metabolic Diseases, Bucharest, Romania. G Tamas, Z Kerenyi, AM Ahmed, J Toth, P Kempler, Tetenyi Teaching Hospital and Semmelweis University, Budapest, Hungary.

S Muntoni, M Songini, M Stabilini, M Fossarello, S Pintus, Ospedale San Michele, Cagliari, Italy.

B Ferriss, CC Cronin, Cork Regional Hospital, Cork, Ireland. M Toeller, A Klischan, T Forst, FA Gries, Diabetes Forschungsinstitut, and $\mathrm{W}$ Wagener, Medizinische Klinik E, Universitat Dusseldorf, Germany.

R Rottiers, H Priem, University Hospital of Gent, Belgium.

P Ebeling, M Sinisalo, VA Koivisto, University Hospital of Helsinki, Finland.

B Idzior-Walus, B Solnica, L Szopinska-Ciba, K Solnica, University School of Medicine, Krakow, Poland.

HMJ Krans, HHPJ Lemkes, JJ Jansen, University Hospital of Leiden, The Netherlands.

J Nunes-Correa, J Boavida, Portuguese Diabetic Association, Lisbon, Portugal.

G Michel, R Wirion, Centre Hospitalier, Luxembourg.

AJM Boulton, H Ashe, DJS Fernando, Manchester Royal Infirmary, UK.

G Pozza, G Slaviero, G Comi, B Fattor, F Bandello, Ospedale San Raffaele, Milan, Italy.

$\mathrm{H}$ Mehnert, A Nuber, H Janka, City Hospital Schwabing, Munich, Germany.

D Ben Soussan, M-C Fallas, P Fallas, Centre Hospitalier de Valenciennes, France.

E Jepson, S McHardy-Young, Central Middlesex Hospital, and JH Fuller, DJ Betteridge, M Milne, University College Hospital, NW London.

G Crepaldi, R Nosadini, Instituto di Medicina Interna, Padua, Italy.

G Cathelineau, B Villatte Cathelineau, M Jellal, N Grodner, P Gervais Feiss, Hospital Saint-Louis, Paris, France.

F Santeusanio, G Rosi, MRM Ventura, C Cagini, C Marino, Instituto di Patologia Medica, Policlinico, Perugia, Italy.

R Navalesi, G Penno, R Miccoli, M Nannipieri, S Manfredi, Instituto di Clinica Medica II, Pisa, Italy.

G Ghirlanda, P Cotroneo, A Manto, C Teodonio, A Minnella, Universita Cattolica del Sacro Cuore, Rome, Italy.

JD Ward, S Tesfaye, C Mody, C Rudd, Royal Hallamshire Hospital, Sheffield, UK. 
GM Molinatti, F Vitelli, M Porta, GF Pagano, P Cavallo Perin, P Estivi, R Sivieri, Q Carta, G. Petraroli, Clinica Medica B, Patologia Medica, Ospedale Molinette, and Ospedale "Agnelli", Turin, Italy.

N Papazoglou, G Manes, G Triantaphyllou, A Ioannides, General Hospital of Thessaloniki, Greece.

M Muggeo, V Cacciatori, F Bellavere, P Galante, ML Gemma, Cattedra di Malatties del Metabolismo, Verona, Italy.

K Irsigler, H Abrahamian, C Gurdet, B Hornlein, C Willinger, Hospital Vienna Lainz, Austria.

S Walford, EV Wardle, New Cross Hospital, Wolverhampton, UK.

G Roglic, Z Resman, Z Metelko, Z Skrabalo, Vuk Vrhovac Institute for Diabetes, Zagreb, Croatia.

Steering Committee Members: JH Fuller (London), H Keen, Chairman (London), HMJ Krans (Leiden), R Navelesi (Pisa), A-K Sjolie (Aarhus), J Stephenson (London), M Toeller (Dusseldorf), G-C Viberti (London), J Ward (Sheffield).

EURODIAB Project Management Group: E Eschwege (Paris), JH Fuller, Project Leader (London), EAM Gale (London), A Green (Odense), B Karamanos (Athens), J Nunes-Correa (Lisbon), L Papoz (Paris), G Pozza (Milan), A Stroobant (Brussels), R Williams (Cambridge).

Co-ordinating Centre: JH Fuller, J Stephenson, M Milne, T Partridge, UCL Medical School, London, UK.

Central Laboratories: G John, The Royal London Hospital, and G-C Viberti, M Mattock, A Collins, R Sharp, Guy's Hospital, London, UK.

Retinopathy Co-ordination: A-K Sjolie, Aarhus University Hospital, Denmark.

Retinopathy Grading Centre: E Kohner, S Aldington, S Cockley, Hammersmith Hospital, London, UK.

\section{References}

1. Bingley PJ, Gale EAM (1989) Rising incidence of IDDM in Europe. Diabetes Care 12: 289-295

2. World Health Organisation (1992) Diabetes care and research in Europe: The St Vincent Declaration Action Programme. WHO, Regional Office for Europe, Copenhagen

3. Chase PH, Jackson WE, Hoops SL, Cockerham RS, Archer PG, O'Brien D (1989) Glucose control and the renal and retinal complications of insulin-dependent diabetes. JAMA 261: $1155-1160$

4. Leslie ND, Sperring MA (1986) Relation of metabolic control to complications of diabetes mellitus. J Pediatrics 108 : 491-497

5. Raskin P, Rosenstock J (1986) Blood glucose control and diabetic complications. Ann Intern Med 105: 254-263

6. Diabetic Retinopathy Study Research Group: report 7 (1981) A modification of the Airlie House classification of diabetic retinopathy. Invest Ophthalmol Vis Sci 21: 210-226

7. Kearney EM, Mount JN, Watts GF, Slavin BM, Kind PRN (1987) Simple immunoturbidometric method for determining urinary albumin at low concentrations using centrifugal analyser. J Clin Path 40: 465-468
8. John GW, Gray MR, Bates DL, Beacham JL (1993) Enzyme immunoassay - a new technique for estimating $\mathrm{HbA}_{1 \mathrm{c}}$. Clin Chem 39: 663-666

9. Ewing DJ, Martyn CN, Young RJ, Clarke BF (1985) The value of cardiovascular autonomic function test: 10 years experience in diabetes. Diabetes Care 8: 491-498

10. Hammersley MS, Holland MR, Walford S, Thorn PA (1985) What happens to defaulters from a diabetic clinic? BMJ 291: 1330-1332

11. Klein R, Klein BEK, Moss SE, Davis MD, DeMets DL (1984) The Wisconsin Epidemiologic Study of diabetic retinopathy. II Prevalence and risk of diabetic retinopathy when age at diagnosis is less than 30 years. Arch Ophthalmol 102: $520-526$

12. Orchard TJ, Dorman JS, Maser RE et al. (1990) Prevalence of complications in IDDM by sex and duration. Pittsburgh Epidemiology of Diabetes Complications Study II. Diabetes 39: $1116-1124$

13. DCCT Research Group (1990) Diabetes Control and Complications Trial (DCCT). Update. Diabetes Care 13:427-433

14. DCCT Research Group (1991) Epidemiology of severe hypoglycaemia in the Diabetes Control and Complications Trial. Am J Med 90: 450-459

15. Klein R, Klein BEK, Moss SE et al. (1988) Glycosylated haemoglobin predicts the incidence and progression of diabetic retinopathy. Ophthalmology 260: 2864-2871

16. Janka HU, Warram JH, Rand LI, Krolewski AS (1989) Risk factors for progression of background retinopathy in longstanding IDDM. Diabetes 38: 460-464

17. MacMahon S, Peto R, Cutler J et al. (1990) Blood pressure, stroke, and coronary heart disease. Part 1, Prolonged differences in blood pressure: prospective observational studies corrected for the regression dilution bias. Lancet 335: 764 774

18. Krolewski AS, Warram JH, Christlieb AR, Busick EJ, Kahn CR (1985) The changing natural history of nephropathy in type 1 diabetes. Am J Med 78: 785-794

19. Andersen AR, Christiansen JS, Andersen JK, Kreiner S, Deckert T (1983) Diabetic nephropathy in type 1 (insulin-dependent) diabetes: an epidemiological study. Diabetologia 25: 496-501

20. Forsblom CM, Groop P-H, Ekstrand A, Groop LC (1992) Predictive value of microalbuminuria in patients with insulindependent diabetes of long duration. BMJ 305: 1051-1053

21. Parving HH, Hommel E, Mathiesen E et al. (1988) Prevalence of microalbuminuria, arterial hypertension, retinopathy and neuropathy in patients with insulin dependent diabetes. BMJ 296: 156-160

22. Boulton AJM, Knight G, Drury P, Ward JD (1985) The prevalence of symptomatic diabetic neuropathy in an insulin treated population. Diabetes Care 8: $125-128$

23. Brown MJ, Asberry AK (1984) Diabetic neuropathy. Ann Neurol 15: 2-12

24. Ziegler D, Mayer P, Muhlen H, Gries FA (1991) The natural history of somatosensory and autonomic nerve dysfunction to glycaemic control during the first 5 years after diagnosis of type 1 (insulin-dependent) diabetes mellitus. Diabetologia 34: $822-829$ 